\title{
Discovering Pedagogical Influences: the Impact of Ethnicity and Gender Representation in Early Childhood Education
}

\author{
Harriett Arnold*, Charlane Starks \\ University of the Pacific \\ *Corresponding Author: harnold@pacific.edu
}

\begin{abstract}
For the past decade, we have written and discussed the importance of teaching and the role of the teacher in the classroom. There continues to be reams of research on the significance of teacher preparation and understanding the implications of ethnicity, gender and diversity within the context of teacher knowledge, skills and dispositions. We suggest that, almost paradoxically, the best way to enhance the human dimension of the learning process is to work on explicitly addressing the same issues through meaningful racial discourse and action research with those who plan to teach in America's schools. We propose to explore the personal development and deeper meanings, seek purpose, and understand the power of transcendence. This article focuses on dolls, gender, discovery and metacognitive thought that are major elements in an action research project set in an undergraduate social justice and diversity course. Discovery by undergraduate third year students was obtained through active involvement, observation, interaction and discourse, reflection, intuition and personal experiences.
\end{abstract}

Keywords Gender, Ethnicity, Early Childhood Education, Pedagogy, Teacher Preparation, Action Research

\section{Introduction}

This article is an account of the Diversity in the Toy Department Action Research Project conducted by twelve early childhood undergraduate students at a central California university. The project involved reflections on scholarly literature, data collection and analysis of a toy store visit as a field experience on the implications of gender and ethnicity in early childhood education. The aim of this study was to address the question, what are the implications of ethnicity and gender for children's toys? In order to address this question, the undergraduate students were interviewed in a focus group setting to discuss their thoughts about the action research project to shed light on ethnicity and gender issues in early childhood education and how those experiences influence adult behavior in the classroom and other spaces such as home environment and higher education classrooms. Certainly the course project challenged students to reflect on past experiences, but more critically, it allowed for meaningful, deeper exploration and transcendence over past circumstances.

\section{Review of Literature}

This project involved several conceptual understandings about what undergraduate students experienced in the project. Students in the course were immersed in an action research project that saw them as the researcher (Mills, 2003). By definition, action research is research conducted by teachers to gain a systemic perspective of a school, teaching, or students' learning (Mills, 2003) in an effort to improve pedagogical practices. Bargal (2006) furthers this idea with his description of the main goal of action research as "to understand the problem to execute interventions for its solution" (p.20). When teachers work collaboratively to understand an issue, the research takes on an even deeper, meaningful endeavor, one that seeks to deconstruct the issue, thus leading to a more transformative experience (Cooper \& Gause, 2007).

While transformation is a powerful experience, suggestive of a change in thoughts or habits, transcendence is even more on display when reflecting deeply on past experiences. We agree with Smith (2000) that transcendence has philosophical and metaphysical meanings (see Biesta, 2011), but we also agree a mere dictionary definition is sufficient and appropriate at least for our purposes. As such, we use the Webster definition of transcendence as the quality or state of going beyond or exceeding usual limits as a lens to examine the course project's impact on students' lives. In her study, Jaime (2008) described the experiences of Native American women, and how each confronted and negotiated their personal experiences which lead them to transcend otherwise 
historical identities. Jaime argued that balanced support from among family, friends and the community are important for maintaining identity. Moreover, she suggested that others with similar experiences with race and gender issues "resist and transcend beyond internalized oppression, racism, sexism and colonization" (no pagination). The exchange from deficit perspectives to more positive perspectives is critically important to the cultural consciousness about self and others. Similarly, Smith (2000) studied three professors' style in which they taught and related to students enrolled in their courses. Her findings suggest several ideas about transcending experience within the classroom. Subject matter should be useful beyond assignments and term paper; thoughtfully designed courses become more transcendent when students are better able to connect lived experiences presently and within course projects and discussions. Smith (2000) puts it this way

If we are to teach students, we must not treat our subjects or their lives as small. Rather we must transcend littleness, inspiring students to learn how their lives connect with the big drama that has been marching forward for three thousand years

In addition to the transcending quality of an action research project, race discourse as a conceptual framework is a particularly useful lens to examine ways in which adults make meaning and relate to others through dialogue in a classroom setting. Doane (2006) asserts racial discourse as "the collective text and talk of society with respect to issues of race... which "is shaped by the changing structure of racial conflict and racial ideologies in the larger society" (p. 256). Teachers are often reluctant to discuss race, gender, and cultural differences (Swindler Boutte \& Lopez-Robertson, 2011). This notion is even more compounded by fact that many of these same discussions are difficult whether in the graduate level teacher programs or in the pre-school setting in an early childhood education center. In her seminal book, Why Are All the Black Kids Sitting Together in the Cafeteria? Tatum (1997) went one step further and challenged readers to look at their own behavior and reflect on the capacity to engage these sorts of transformative racial discourse. Using a familiar item such as dolls to discuss race and gender issues can lead to insightful discussions thus having a profound impact of classroom activities. In a study of several toy stores in the mid-western states, Hofmann (2009) investigated stores to record data on toy manufacturers. Findings from the study suggest that the power and labor inequities in home and work places are often shaped and defined in the types of toys that are mindlessly thrown in the shopping cart" (Hofmann, 2009, p. 33).

The growth in literature on ways to combat struggles with inequities that may surface in classroom environments is helpful for both novice and experience early childhood educators who may encounter difficult exchanges on race and gender issues in their classroom. Studies suggests adult often assume children are not aware of race equalities, nor are they cognitively prepared or experienced enough for conversations about race (Doucet \& Keys Adair, 2013;
Husband, 2010) or gender equity in media portrayals (Aina \& Cameron, 2011). However, studies also show that with care and tact, children are indeed able to converse and make meaning of race and gender issues. For example, Bentley (2012) chronicled understandings related to multiculturalism and social justice in her pre-kindergarten classroom and school settings. The author argued that one-dimensional displays of multiculturalism could be transcended into more meaningful actions and conversations even for the youngest of learners. Her findings suggest teachable moments and conversations and creating connections to multiculturalism and social justice issues are critical for addressing such complex understandings. In the end, early children educators can prepare future teachers with enlightened and critical discussions about race and gender issues in the classroom. By doing so, teachers can begin to understand how power and privilege, media and social influence of equal representations can infiltrate early childhood classrooms thus enabling them to promote positive images in society (Doucet \& Keys Adair, 2013; Giovacco-Johnson, 2011; Husband, 2012; Maher, Herbst, Childs, \& Finn, 2008). We answered this call for critical interactions and preparation with a course project that increased awareness and offered opportunity to transcend previous ideas of race and gender equity.

\section{Methods}

The research questions guiding this examination include: what are the implications of ethnicity and gender for children's toys? To answer this question, undergraduate students studying social justice and diversity in early childhood education were given the course culminating project, The Diversity in the Toy Department Action Research Project. The project involved developing and implementing a study to a local toy store to record data on the ethnicity and packaging of dolls, bicycles and other toys in the store. Prior to their data collection, students worked in groups to discuss such items as what to include in the final report, data collection methods; what counts as data such as cultural messages, advertisements; data analysis techniques.

The projects presented in the course formed the basis for the focus group discussion. Gathering data from a focused small group discussion as a methodological approach to research is useful since it provides for a less threatening setting (Krueger \& Casey, 2000; Wilkinson, 2004). The data gathered from this focus group meeting with the undergraduate students was conducted shortly after the students presented their finding in the classroom. The student participants agreed to participate in an open-ended interview setting. Patton (2012) suggests conversational interviews supports flexibility in "pursuing information in whatever direction the conversation seems to being taking" (Patton, 2012, p.342). The conversational interview followed closely the conversation styles meetings with the course instructor who had built the trust among the students 
well enough that the focus group setting allow for spontaneous conversation. While questions asked during a conversational interview are not predetermined, an interview protocol listed several questions to guide the conversation about race and equity in order to illuminate these issues within the conversation. Further, the time to conduct the group conversation placed limitations may have prevented more emergent experiences and individual perspectives during the meeting.

\section{Participants}

The participants in this study had been meeting as class prior to data collection, so they have some familiarity with each other. Twelve students were assigned the project, however only eight of those students chose to participate. They gave consent to use their words verbatim and were assigned pseudonyms in the study. The eight students were participants in a central California valley college early childhood education program. Student demographical backgrounds included an age range of 20 s to late 40 s and from a multiple cultural backgrounds including-Cambodian, Latina, Caucasian, and African American.

\section{Data Analysis}

The focused conversational interviews recorded notes were transcribed and pre-coded for instances of race, gender, and equity initial. A second coding was performed in the style of a grounded theoretical framework approach to data analysis (Creswell, 2013). Nine categorical headings were generated and accounted for based on the data collected in the study (Creswell, 2013). The analyzed data developed into several themes that began to emerge from the data.

\section{Findings}

\section{Media and Marketing Influences}

Media and marketing was a major point in the focus for discussion. Students felt that the media and marketing were powerful indicators of what they felt about their self-image. Indeed, some noted that their experience with racial differences had an effect on their self-image. Students reacted to the experience with remembrances of not seeing dolls that looked like them-brown-skinned Barbies and not just the white-skinned Barbies they had seen in televisions advertisements. One of the participants remarked that early in life, she noticed differences about race from media outlets such as print advertising and television programming. And as one group member stated, "I'm not a racist, I just wanted a doll that looked like me."

\section{Self-Image}

I was older...probably middle school. I guess that's when I remember feeling different...you're going through puberty, getting more curves, and uh...u know... I had braces and my hair was really dark, you know like black not light brown...I remember thinking I was different. I felt like I wasn't who I wanted to be...

Children are aware of what they see on television and other media outlets, and many of their purchasing desires could clash with their realities of life and community (Maher, Herbst, Childs, \& Finn, 2008). Television advertisements contrasted with students conducting the field experiment saw as young children growing up in a variety of culturally diverse communities.

Participant Darla, a self-described curious kid, would always look for Hispanic dolls when she went to the toy store with her parents, and then questioned, "Where are they?" Indeed, children ask powerful, revealing questions when given the opportunity. Darla remembered asking the store manager of her local toy store a daring question about where all the Hispanic dolls were only to be told the closest, available ethnic doll was an African American doll. The students in this group nervously chuckle at the thought that such statements would be seen as being a racially charged thought, but it was much more. The truth is, Darla and others wanted to buy a doll that looked somewhat like them.

Not that I was racist...I would play with all kinds of

dolls. It was scary...I just wondered where was the Asian doll or the Hispanic doll.

The students again laughed a nervous laugh, but the stories about their first experiences ethnic and gender biases are still vivid images of how they were making sense about race, gender as well as class. Several of the students' recounted their parents shielding them children from the callous realities of isms in the toy store-racism, classism, and sexism. Students described times when parents kept them home to avoid awkward movements and stares of store employees thinking that one of the family members were apt to steal rather than buy from the store.

\section{Changed Perceptions}

During the project, students began to unpack ways in which some of their childhood encounters and experiences have influenced their perceptions of race and gender representations as adults, including the professional work as preschool teachers. Students spoke passionately about these experiences as they began to talk more frank and open about the difficult conversations of race and class and the impact it could have in classroom settings. These experiences whether grounded in southern states experiences growing up in the 1960s or a native Californian growing up in a white American suburban community seemed to blend together past and current experiences as participants shared their stories about toys stores.

I remember when I was eight years old, they took us to the Schwinn Store and it was on East Main Street... That was the time when people were actually pleasant to us. My mom said," I guess they figure we can't steal a bike out of the store...were looking at the early sixties. 
The experience of visiting a toy store as an adult learner helped several of the students reflect on how this project heightened their perceptions of race and class in the classroom. The students also described feelings of being upset and concerned about the class images and the lack of ethnicity among the toy selections. They described being more empathetic to diverse cultures.

I remember looking for something I'd see on an ad, but it was always white, blond dolls, but I never remembered seeing a Hispanic or African American...or something other than white and blond.

Participant Mary emigrated from Cambodia at seven years old and remembered the excitement from receiving toys from her parents who bought the toys on half of Mary and her siblings. Presently as a pre-school teacher, she is keenly aware of toys and the many variations, but hoped to see gender specific variations in terms of roles and classes in society. Moreover, they students observed that they are more willing to look deeper and carefully observe the cultural details of their own classrooms. Indeed, some pledged to intentionally find toys that are more reflective of their students' cultural backgrounds. The toy store project dramatized for several of the students a need for authentic cultural representations in the classroom even to the point of ensuring toys have facial features that are similar to those of their students.

... as educators we need to be able to reach out to the parents to help them feel more comfortable about discussing these issues with their children as well as we're trying to the children to understand the diversity and how to treat others.

\section{Discussion}

The present study examined the experiences of eight undergraduate students' action research project to examine dolls in a local toy store. The Diversity in the Toy Department Action Research Project for this group of early childhood education students was a game changer in term of race, gender, and culture in the classroom. The semester long project required students to examine and question marketed images and identities on packaged toys. Students needed the time to develop trust in a meta-structural process involving the course instructor and other students (Frusciante, 2008). Often discussions about race and gender issues in classroom can be uncomfortable and inhibited for various reasons such lack of trust, fear, and doubts, and vulnerability. Thus it would be incumbent upon the course instructor to provide a safe place for students to hear each other's voice through writings (Frusciante, 2008), presentations, projects, and other academic expressions.

In addition to participating in action research by gathering data, analyzing it, and writing a report about their findings, this group of early childhood education students experienced it. In everyday living spaces and interactions with others, unrecognizable racial and gender identities prescribed through marketed images require constant unpacking and reflection. As such, early childhood educators and students alike can reflect on ways in which race and gender and even class operate in personal and professional arenas (Husband, 2012). Consistent with Tatum's (1997) research on earliest remembrances of race-related memories, the participants revealed candid and vivid remembrances of race discourse as well as incidences based on ethnicity or gender. As early as pre-school age, children begin to notice differences in terms of hair texture and skin color (Tatum, 1997). Several of the participants talked of skin color differences portrayed in the media and even in the home environment, and quite naturally these images have remained as deep-seeded reminders of the effects of racial experiences in early childhood. When teacher educators provide multiple, meaningful opportunities to engage race and gender issues, students have opportunity to transcend personal, negative feelings and experience toward "developing a more critical consciousness" (Husband, 2012, p. 270) of these issues in their own early childhood education classrooms.

\section{Conclusion}

Race discourse in undergraduate programs can be a slippery slope for even the most experienced teacher educators. Projects like the Diversity in the Toy Department Action Research project can provide a safe venue for students to discover how gender and ethnicity representations impact early childhood education. The vulnerabilities of discussing race and gender issues are important to realize as they prompt many students to question their own biases and mind-set associated with these constructs.

Action research can provide an avenue for discovering, and in many ways, uncovering images of race and gender portrayed and the continuation of such issues through the simplest yet powerful transmission of social images to children. Regardless of how race and gender images are passed intergenerational or through the media, teacher educators and teachers need to become facilitators involving students in self-discovering activities that will deconstruct those images through meaningful discussions and reflections about its impact in the classroom.

There are variations in culture, language, ideologies, geographic areas and numerous factors to reflect the complexities that must be taken into account when addressing the influences of ethnicity and gender in the early childhood classroom. This project sought to explore the personal development and deeper meanings, seek purpose, and understand the power of transcendence. Each week there would be issues of social justice and diversity indicated on the course syllabus for the students but this assignment provided an opportunity for reality, navigation and professional development all areas that were missing from the listed course information. The students were willing to demonstrate trust and respect by sharing their inner most 
concerns and personal lives with each other. The results reflected that students were transformed and were no longer bystanders in their lives but became leaders sharing, caring and learning about the topics and each other. There were multiple opportunities to move from multiple sets of skills, knowledge and understanding to complex issues that had meaning for each of them into the future.

\section{REFERENCES}

Aina, O.E., \& Cameron, P.A. (2011). Why does gender matter? Counteracting stereotypes with young children. Dimensions of Early Childhood, 39(3), 11-19.

Bargal, D. (2008). Action research: A paradigm for achieving social change. Small Group Research, 39(1), 17-27. doi: $10.1177 / 1046496407313407$.

Bentley, D.F. (2012). (Guest Editorial) "Rights are the words for being fair": Multicultural practice in the early childhood classroom. Early Childhood Education Journal, 40, 195-202. doi: 10.1007/s10643-011-0492-7.

Biesta, G. (2011). Transcendence, revelation, and the constructivist classroom: Or, in praise of teaching. Philosophy of Education, 358-365.

Cooper, C., \& Gause, C.P. (2007). "Who's afraid of the big bad wolf?" Facing identity politics and resistance when teaching for social justice. In D. Carlson \& C.P. Gause (Eds.), Keeping the promise: Essays on leadership, democracy, and education. (pp.197-216). New York: Peter Lang.

Creswell, J. (2013). Qualitative inquiry \& research design: Choosing among five approaches. (3rd. ed.). Los Angeles: Sage.

Doucet, F., \& Keys Adair, J. (November 2013). Addressing race and inequity in the classroom. Young Children, 88-97.

Frusciante, A. (2008). Identifying transcendence in educating for example for public service: Reflections on qualifying to teaching as a pedagogic example. Teaching in Higher Education, 13(6), 679-689.

Giovacco-Johnson, T. (2011). Applied ethics as a foundation in early childhood teacher education: Exploring the connections and possibilities. Early Childhood Education Journal, 38, 449-456. Doi: 10.1007/s10643-010-0428-7

Hofmann, S. (2005). Miles of Aisles of Sexism: Helping students investigate toy stores. Rethinking Schools, 20(2), 29-33.

Husband, T. (2010). He's too young to learn about that stuff: Antiracist pedagogy and early childhood social studies. Social Studies Research and Practice, 5(2), 61-75.

Husband Jr, T. (2012). Guest Editorial "I don't see color": Challenging assumptions about discussing race with young children. Early Childhood Education Journal, 39, 365-371. doi: 10.1007/s10643-011-0458-9

Jaime, A.M. (2008). Native women: decolonization and transcendence of identity. International Journal of Multicultural Education, 10(2).

Krueger, R. A., \& Casey, M. A. (2000). Focus groups: A practical guide for applied researchers (3rd ed.). Thousand Oaks, CA: Sage.

Maher, J.K., Herbst, K.C., Childs, N.M., \& Finn, S. (2008). Racial stereotypes in children's television commercials. Journal of Advertising, 48(1) 80-93. doi: 10.2501/50021849908080100.

Mills, G.E. (2003). Action research: A guide for the teacher researcher. Upper Saddle River, NJ: Merrill Prentice Hall.

Patton, M. (2002). Qualitative research \& evaluation methods. (3rd. ed.). Thousand Oaks: Sage.

Smith, M.J. (2000). (Editor's Choice) Caring, community and transcendence-Developing spirit to improve learning. Community College Review, 28(3), 57-74.

Swindler Boutte, G., Lopez-Robertson, J., \& Powers-Costello, J. (2011). Moving beyond colorblindness in early childhood classrooms. Early Childhood Education Journal 39, 335-342. doi: 10.1007/s10643-0110457-x.

Tatum, B.D. (1997). "Why are all the black kids sitting together in the cafeteria? And other conversations about race. New York: Basic Books.

Tatum, B.D. (2007). Can we talk about race? And other conversations in an era of school resegregation. Boston: Beacon Press.

Wilkinson, S. (2004). Focus group research. In D. Silverman (ed.), Qualitative research: Theory, method, and practice (pp. 177-199). Thousand Oaks, CA: 